\title{
Earth Pressure on Retaining Wall with Surface-Inclined Cohesive Fill Based on Principal Stress Rotation
}

\author{
Hengli Wang $\mathbb{D}^{1,2,3}$ Zhengsheng Zou $\mathbb{D}^{1,2,3}{ }^{1,3 a n}$ Liu, $^{4}$ and Xinyu Wang ${ }^{1,2,3}$ \\ ${ }^{1}$ College of Civil Engineering, Henan Polytechnic University, Jiaozuo, Henan 454003, China \\ ${ }^{2}$ International Joint Research Laboratory of Henan Province for Underground Space Development and Disaster Prevention, Jiaozuo, \\ Henan 454003, China \\ ${ }^{3}$ Henan Key Laboratory of Underground Engineering and Disaster Prevention, Jiaozuo, Henan 454003, China \\ ${ }^{4}$ China Railway 16th Bureau Group Co., Ltd., Chaoyang District, Beijing 100018, China \\ Correspondence should be addressed to Zhengsheng Zou; zouzs@hpu.edu.cn
}

Received 23 September 2021; Accepted 21 October 2021; Published 3 November 2021

Academic Editor: Haojie Lian

Copyright (C) 2021 Hengli Wang et al. This is an open access article distributed under the Creative Commons Attribution License, which permits unrestricted use, distribution, and reproduction in any medium, provided the original work is properly cited.

\begin{abstract}
When considering the friction and bonding force between the back of the retaining wall and the horizontal fill behind the wall, the principal stress of the soil element near the vertical back of the retaining wall is no longer vertical and horizontal but deflects to a certain extent. When the surface of the backfill becomes inclined, the principal stress of the soil behind the wall deflects in a more complicated way. In this paper, the cohesion of the soil element in the fill with an inclined surface is assumed, and the formulas for calculating the active and passive earth pressures of the retaining wall with inclined cohesive backfill are derived by rotating the principal stress of the soil element behind the wall. The proposed method is compared with the existing algorithm, and the influences of the inclination and the cohesion of the fill are analyzed. The results show that the proposed method is more universal. Both the active and passive earth pressures increase rapidly with the increase of the inclination of the fill. The active earth pressure and its horizontal component decrease with the increase of the cohesion of the fill, while the passive earth pressure and its horizontal component increase with the increase of the cohesion of the fill.
\end{abstract}

\section{Introduction}

The calculation of earth pressure is the precondition of designing a retaining wall, and the calculation results directly affect the rationality of design. Rankine's earth pressure theory and Coulomb's earth pressure theory are classical algorithms for calculating earth pressure, but there are some deviations between their assumptions and practical engineering. According to the actual engineering situation, researchers adopt different methods and ways to revise, supplement, or expand the classical earth pressure theories.

Based on Coulomb's earth pressure theory, Wang established a calculation method for earth pressure of cohesionless backfill retaining wall under uniform overloading by using the horizontal plate element method and through the force balance analysis on the soil element [1]. Later, many researchers established the calculation formula for active earth pressure of a rigid retaining wall without cohesive backfill based on the assumption of a plane slip surface and considering the arching effect in the backfill of the wall with an improved horizontal plate element method [2-4]. In addition, some researchers adopted the pseudodynamic method and the horizontal plate element method to analyze the soil wedge behind the wall and established the seismic earth pressure calculation method for the rigid retaining wall with cohesionless backfill [5, 6]. Besides, Pain et al. [7] established a calculation method for calculating the passive earth pressure by using a pseudostatic method and considering the arching effect in the fill behind the wall and the friction of the wall-soil interface. In the study of seismic earth pressure, some researchers established the calculation formula of seismic earth pressure for cohesionless backfill considering the amplification effect of soil mass [8-10]. Based on the redistribution principle, Maskar and Madhekar [11] established 
the calculation equation of seismic active earth pressure strength of cohesionless soil considering the earthquake action.

In practical engineering, the fill behind the wall is mostly cohesive soil, so some researchers have studied the calculation method of the earth pressure of cohesive fill. For example, Mazindrani and Ganjali [12] established active and passive earth pressure coefficient tables by analyzing the stress circle of inclined cohesive fill and gave an application example. In addition, Gnanapragasam [13] established the calculation formula of active earth pressure distribution of the retaining wall with cohesive fill by analyzing the stress of inclined cohesive fill. Based on the assumption of the plane sliding surface, Shukla et al. [14] established the calculation method of seismic earth pressure of retaining wall with cohesive fill through the force analysis of soil behind the wall. However, these methods ignored the interaction between the retaining wall and the cohesive backfill. Later, Shukla [15] gave the expression of active earth pressure under static and seismic loads, taking into account the interaction of the wall-soil bonding force, but did not consider the effect of the wall-soil friction. Besides, Peng and Zhu [16] took into account the effect of friction and bonding force on the wall-soil interface, analyzed the soil behind the wall by using the horizontal strip method, and derived the calculation formula of the active earth pressure distribution of the cohesive soil according to the mutual equality theorem of shear stress. Irdmoosa and Shahir [17, 18] established the calculation method of earth pressure for the retaining wall with cohesive backfill based on the assumption of principal stress rotation, taking into account the action of soil arch in the backfill and the interaction of friction and bonding force at the wall-soil interface. But these methods can only be used to calculate the earth pressure of the retaining wall with horizontal fill. Based on the limit equilibrium theory, some researchers analyzed the force of soil behind the wall and deduced the calculation method of earth pressure of inclined cohesive filling by considering the interaction of friction and bonding force at the wallsoil interface [19-21], and Vahedifard et al. [22] established the calculation method of active earth pressure of inclined cohesive soil under the condition of unsaturated steady flow based on the effective stress analysis of limit equilibrium. It should be noted that the above researchers assumed that the angle between the earth pressure acting on the wall back and the normal of the wall back is the angle of wall-soil friction. The results showed that the interaction between the retaining wall and the backfill behind the wall is not fully considered when the direction of earth pressure is limited [23].

The existence of the friction and bonding force between the back of the retaining wall and the backfill makes the principal stress in the soil near the vertical back of the retaining wall no longer in the vertical and horizontal directions, but in a certain degree of deflection. When the surface of the backfill becomes inclined, the deflection of principal stress is more complicated. In view of the deflection of the principal stress of the soil behind the wall, Lancellota [24] established the calculation method of active and passive earth pressure of retaining wall with the horizontal surface of the cohesionless fill behind the wall based on the plastic lower bound theorem and considering the effect of the wall-soil friction by adopting the principal stress rotation method. Later, some researchers further considered the influence of inclined fill and adopted the principal stress rotation method to establish the calculation formula of seismic earth pressure of the retaining wall with cohesionless fill $[25,26]$. Wang et al. [27] adopted the principal stress rotation method to derive the calculation method of active and passive earth pressures of the retaining wall with vertical back and horizontal surface of cohesive fill. However, the results of applying the principal stress rotation method to the inclined surface of cohesive fill have not been reported.

In this paper, the retaining wall of semi-infinite cohesive fill with an inclined surface is studied, and the effects of wallsoil friction and wall-soil bonding force are considered. Based on the principal stress rotation method, the calculation formulas of active and passive earth pressure of the retaining wall with inclined cohesive fill are derived, and the effects of the surface inclination of the fill and the cohesion of the fill on the earth pressure are analyzed.

\section{Calculation of Passive Earth Pressure}

For the infinite soil with an inclined surface, the vertical selfweight stress of the soil is the same at any same depth below the inclined surface of the fill. The angle between the inclined surface and the horizontal plane of the backfill is set as $\beta(\beta<\varphi)$, and the soil strip with unit width is taken for research (Figure 1); then, the earth pressure strength on the inclined plane $b c$ is obtained [28]:

$$
\sigma=\gamma z \cos \beta
$$

The normal and tangential strengths on the $b c$ plane are as follows:

$$
\begin{gathered}
\sigma_{z z}=\gamma z \cos ^{2} \beta, \\
\tau_{z z}=\gamma z \cos \beta \sin \beta .
\end{gathered}
$$

For the soil element on the back of the retaining wall, based on the bonding force and friction of the wall-soil interface, its shear strength can be obtained [28]:

$$
\tau=c_{w}+\sigma_{x x} \tan \delta
$$

where $c_{w}$ is the bonding force of the wall-soil interface, $\sigma_{x x}$ is the normal stress of inclined backfill element, and $\delta$ is the angle of the wall-soil friction.

For the passive retaining wall, the soil behind the wall will be in two different stress states due to the influence of the friction and bonding force at the wall-soil interface and the inclined filling behind the wall, as shown in Figure 2. The soil element in region $b$ far from the wall is affected by the gravity stress of the inclined fill, and the direction of the principal stress deflects relative to the vertical and horizontal directions. The principal stress of the soil element in 


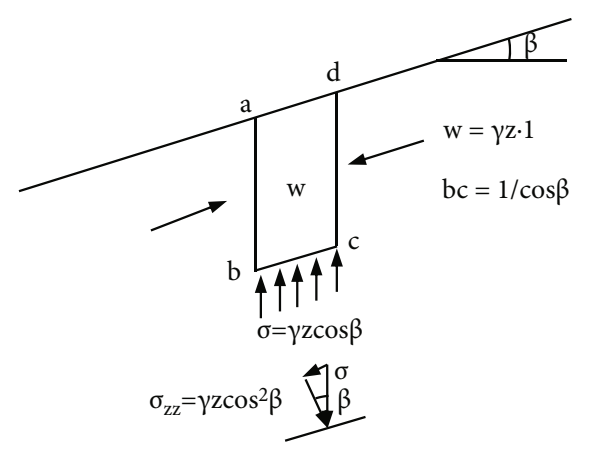

FIgURE 1: The stress vector on the plane parallel to the inclined surface.

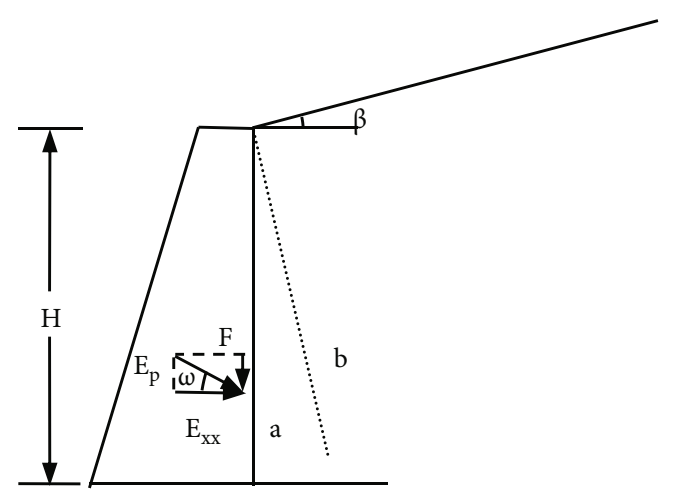

FIGURE 2: Retaining wall under passive limit state.

region $a$ behind the wall deflects to a certain extent due to the friction and bonding force of the wall-soil interface. This results in a jump in the direction and magnitude of the principal stress at the interface between the two stress states of regions $a$ and $b$. The variation of the stress magnitude and direction on the interface is analyzed, and the method of stress rotation is adopted.

The stress circles of soil in regions $a$ and $b$ behind the passive retaining wall are drawn in Figure 3. In order to facilitate analysis, the $\tau$ axis of the stress circle diagram of clay is shifted $l(l=c \cot \varphi)$ to the left, which obtains a new coordinate system with the coordinate origin of $(0,0)$, as shown in Figure 3, where $s^{\prime}=s+l, \sigma_{x x}^{\prime}=\sigma_{x x}+l$. The abscissa of the center of stress circle 2 of the soil behind the wall is $s_{2}^{\prime}$. The rotation of the principal stress direction is assumed to be a finite value $\theta$, and stress circle 1 of the soil on the back of the wall is obtained, and the abscissa of the center of stress circle 1 is $s_{1}^{\prime}$. The following relationship between the abscissa of the two stress centers is as follows:

$$
\frac{s_{1}^{\prime}}{s_{2}^{\prime}}=e^{2 \theta \tan \varphi} .
$$

Terzaghi [28] studied the cohesive fill with an inclined surface and neglected the effect of cohesion on the soil element in the process of stress analysis of the soil element of inclined fill. In order to take into account the effect of the cohesion, the inclination of the fill behind the wall is $\beta$, and it is assumed that the cohesion between soil elements is as follows:

$$
c_{m}=c \cdot \frac{\tan \beta}{\tan \varphi} .
$$

According to stress circle 2 after the deflection of the principal stress rotation caused by the filling with an inclined surface (Figure 3 ), the following geometric relations can be obtained:

$$
\begin{gathered}
O^{\prime} H_{2}=s_{2}^{\prime} \cos \beta, \\
H_{2} M=\sqrt{r_{2}^{2}-R_{2} H_{2}^{2}}=s_{2}^{\prime} \sqrt{\sin ^{2} \varphi-\sin ^{2} \beta}, \\
O^{\prime} M=O^{\prime} H_{2}-H_{2} M .
\end{gathered}
$$

The principal stress of the soil element of the cohesive fill due to an inclined surface is as follows:

$$
\begin{gathered}
O M=\gamma z \cos \beta, \\
\sigma_{z z}^{\prime}=\gamma z \cos ^{2} \beta+c \cot \varphi .
\end{gathered}
$$

The following equation can be obtained through geometric analysis:

$$
O^{\prime} M=\frac{\sigma_{z z}^{\prime}}{\cos \beta}=s_{2}^{\prime}\left(\cos \beta-\sqrt{\sin ^{2} \varphi-\sin ^{2} \beta}\right) .
$$

According to stress circle 1 (Figure 3) after deflection of the principal stress direction caused by friction and bonding force between the wall and the backfill, the following geometric relations can be obtained:

$$
\begin{gathered}
O^{\prime} C_{1}=O^{\prime} H_{1}=s_{1}^{\prime} \cos \delta, \\
C_{1} T=H_{1} A=\sqrt{r_{1}^{2}-H_{1} R_{1}^{2}}=s_{1}^{\prime} \sqrt{\sin ^{2} \varphi-\sin ^{2} \delta}, \\
O^{\prime} T=O^{\prime} C_{1}+C_{1} T=s_{1}^{\prime}\left(\cos \delta+\sqrt{\sin ^{2} \varphi-\sin ^{2} \delta}\right), \\
\sigma_{x x}^{\prime}=O^{\prime} T \cos \delta .
\end{gathered}
$$

The following equation can be obtained through geometric analysis:

$$
\sigma_{x x}^{\prime}=s_{1}^{\prime} \cos \delta\left(\cos \delta+\sqrt{\sin ^{2} \varphi-\sin ^{2} \delta}\right),
$$

where $\delta$ is the friction angle between the wall back and the fill. 


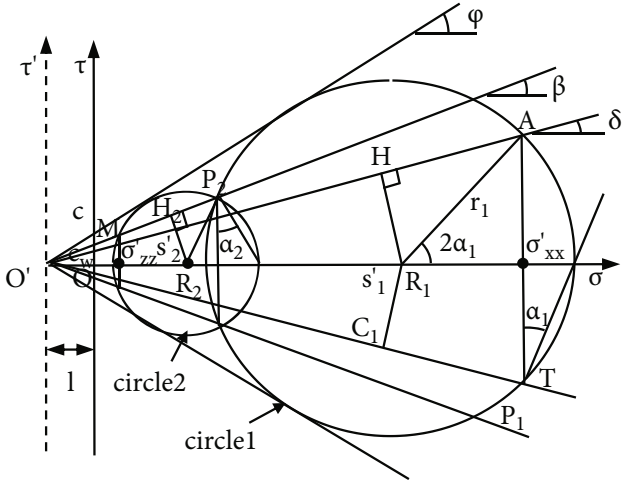

(a)

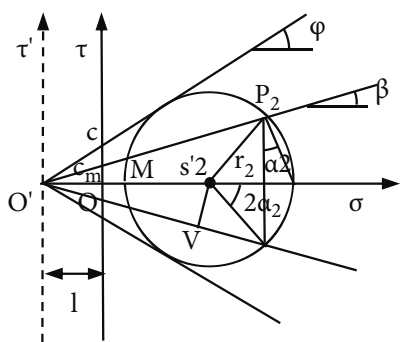

(b)

Figure 3: The passive earth pressure stress circle.

The formula is further deformed to

$$
\begin{aligned}
& \sigma_{x x}^{\prime}=\frac{s_{1}^{\prime}}{s_{2}^{\prime}} \frac{\cos \delta\left(\cos \delta+\sqrt{\sin ^{2} \varphi-\sin ^{2} \delta}\right)}{\cos \beta-\sqrt{\sin ^{2} \varphi-\sin ^{2} \beta}} \cdot \frac{\left(\gamma z \cos ^{2} \beta+c \cot \varphi\right)}{\cos \beta} \\
& =\frac{\cos \delta\left(\cos \delta+\sqrt{\sin ^{2} \varphi-\sin ^{2} \delta}\right)}{\cos \beta\left(\cos \beta-\sqrt{\sin ^{2} \varphi-\sin ^{2} \beta}\right)} e^{2 \theta \tan \varphi} \cdot\left(\gamma z \cos ^{2} \beta+c \cot \varphi\right) .
\end{aligned}
$$

The horizontal component of the passive earth pressure strength is as follows:

$$
\begin{aligned}
\sigma_{x x}= & \sigma_{x x}^{\prime}-l=\frac{\cos \delta\left(\cos \delta+\sqrt{\sin ^{2} \varphi-\sin ^{2} \delta}\right)}{\cos \beta\left(\cos \beta-\sqrt{\sin ^{2} \varphi-\sin ^{2} \beta}\right)} e^{2 \theta_{p} \tan \varphi} \\
& \cdot\left(\gamma z \cos ^{2} \beta+c \cot \varphi\right)-c \cot \varphi=K_{p 1 x} \gamma z \\
& +K_{p 2 x} c \cot \varphi-c \cot \varphi,
\end{aligned}
$$

where

$$
\begin{gathered}
K_{p 1 x}=\frac{\cos \delta \cos \beta\left(\cos \delta+\sqrt{\sin ^{2} \varphi-\sin ^{2} \delta}\right)}{\cos \beta-\sqrt{\sin ^{2} \varphi-\sin ^{2} \beta}} e^{2 \theta_{p} \tan \varphi}, \\
K_{p 2 x}=\frac{\cos \delta\left(\cos \delta+\sqrt{\sin ^{2} \varphi-\sin ^{2} \delta}\right)}{\cos \beta\left(\cos \beta-\sqrt{\sin ^{2} \varphi-\sin ^{2} \beta}\right)} e^{2 \theta_{p} \tan \varphi} .
\end{gathered}
$$

The vertical component of the passive earth pressure strength is as follows:

$$
\begin{aligned}
\tau & =O^{\prime} T \sin \delta=\frac{s_{1}^{\prime}}{s_{2}^{\prime} \sin \delta\left(\cos \beta\left(\cos \beta-\sqrt{\sin ^{2} \varphi-\sin ^{2} \delta-\sin ^{2} \beta}\right)\right.} \cdot\left(\gamma z \cos ^{2} \beta+c \cot \varphi\right) \\
& =\frac{\sin \delta\left(\cos \delta+\sqrt{\sin ^{2} \varphi-\sin ^{2} \delta}\right)}{\cos \beta\left(\cos \beta-\sqrt{\sin ^{2} \varphi-\sin ^{2} \beta}\right)} e^{2 \theta_{p} \tan \varphi} \cdot\left(\gamma z \cos ^{2} \beta+c \cot \varphi\right) \\
& =K_{p 1 y} \gamma z+K_{p 2 y} c \cot \varphi,
\end{aligned}
$$

where

$$
\begin{gathered}
K_{p 1 y}=\frac{\sin \delta \cos \beta\left(\cos \delta+\sqrt{\sin ^{2} \varphi-\sin ^{2} \delta}\right)}{\cos \beta-\sqrt{\sin ^{2} \varphi-\sin ^{2} \beta}} e^{2 \theta_{p} \tan \varphi}, \\
K_{p 2 y}=\frac{\sin \delta\left(\cos \delta+\sqrt{\sin ^{2} \varphi-\sin ^{2} \delta}\right)}{\cos \beta\left(\cos \beta-\sqrt{\sin ^{2} \varphi-\sin ^{2} \beta}\right)} e^{2 \theta_{p} \tan \varphi} .
\end{gathered}
$$

The passive earth pressure strength is as follows:

$$
\sigma_{p}=\sqrt{\sigma_{x x}^{2}+\tau^{2}} .
$$

The vertical component of passive earth pressure is as follows:

$$
F=\int_{0}^{H} \tau d z=\frac{1}{2} \gamma H^{2} K_{p 1 y}+K_{p 2 y} c H \cot \varphi .
$$

The horizontal component of passive earth pressure is as follows:

$$
E_{x x}=\int_{0}^{H} \sigma_{x x} d z=\frac{1}{2} \gamma H^{2} K_{p 1 x}+K_{p 2 x} c H \cot \varphi-c H \cot \varphi .
$$

The passive earth pressure is as follows:

$$
E_{p}=\sqrt{E_{x x}^{2}+F^{2}} .
$$

The included angle between the action direction of passive earth pressure and the normal of wall back is as follows:

$$
\omega_{p}=\arctan \frac{F}{E_{x x}} .
$$

From circle 1 in Figure 3, the following equations are obtained: 


$$
\begin{gathered}
H_{1} R_{1}=O^{\prime} R_{1} \sin \delta=\frac{r_{1}}{\sin \varphi} \sin \delta, \\
\sin \left(2 \alpha_{1}-\delta\right)=\frac{\sin \delta}{\sin \varphi} .
\end{gathered}
$$

From circle 2 in Figure 3, the following equations are obtained:

$$
\begin{gathered}
H_{2} R_{2}=O^{\prime} R_{2} \sin \beta=\frac{r_{2}}{\sin \varphi} \sin \beta, \\
\sin \left(2 \alpha_{2}-\beta\right)=\frac{\sin \beta}{\sin \varphi} .
\end{gathered}
$$

It can be seen from Figure 3 that

$2 \theta_{p}=2\left(\alpha_{1}+\alpha_{2}\right)=\arcsin \left(\frac{\sin \delta}{\sin \varphi}\right)+\arcsin \left(\frac{\sin \beta}{\sin \varphi}\right)+\delta+\beta$,

where $\alpha_{1}$ is the deflection angle of the principal stress of the cohesive soil element caused by the friction and bonding force between the retaining wall and the backfill and $\alpha_{2}$ is the deflection angle of principal stress of the cohesive soil element caused by the inclined surface of the cohesive backfill behind the wall.

According to Figure 3, the relationship between the bonding force of the wall-soil interface $\left(c_{w}\right)$, the friction angle of the wall-soil interface $(\delta)$, the cohesion of the fill $(c)$, and the internal friction angle of the fill $(\varphi)$ are as follows:

$$
c_{w}=c \cdot \frac{\tan \delta}{\tan \varphi}
$$

If the fill behind the wall is cohesionless soil $(c=0)$, then Equation (12) degenerates into the following equation:

$$
\sigma_{x x}=K_{p} \gamma z
$$

where

$$
K_{p}=\frac{\cos \delta \cos \beta\left(\cos \delta+\sqrt{\sin ^{2} \varphi-\sin ^{2} \delta}\right)}{\cos \beta-\sqrt{\sin ^{2} \varphi-\sin ^{2} \beta}} e^{2 \theta_{p} \tan \varphi} .
$$

It is completely consistent with Lancellota's passive earth pressure formula for the retaining wall with inclined cohesionless fill [29].

If the back of the wall is smooth $(\delta=0)$ and the backfill level $(\beta=0)$, then $\theta_{p}=0, c_{w}=0$, and Equation (19) degenerates into the following equation:

$$
E_{p}=1 / 2 \gamma H^{2} K_{p}+2 c H \sqrt{K_{p}},
$$

where

$$
K_{p}=\frac{1+\sin \varphi}{1-\sin \varphi}=\tan ^{2}\left(45^{\circ}+\frac{\varphi}{2}\right) .
$$

This means that for the retaining wall with horizontal backfill, the calculation formula of passive earth pressure in this paper is the same as the formula of Rankine passive earth pressure if the friction and bonding force of the wallsoil interface are not considered.

\section{Calculation of Active Earth Pressure}

For the retaining wall in an active state (Figure 4), the stress state of the soil behind the wall also has a jump. Taking the soil element at the back of the wall and behind the wall for analysis, the molar stress circles of the soil at the back of the active retaining wall and behind the wall are shown in Figure 5. The $\tau$ axis is shifted $l(l=c \cot \varphi)$ to the left by the same method, where the stress circle 1 is the stress circle of the soil element behind the wall, and the abscissa of the center of the stress circle is $s_{1}^{\prime}$, while the direction of principal stress is deflected due to the inclination of the fill. Stress circle 2 is the stress circle of the soil on the back of the wall, and the abscissa of the center of the stress circle is $s^{\prime}{ }_{2}$, while the direction of principal stress is deflected due to the friction and bonding force of the wall-soil interface.

Similarly, there is the following relationship between the abscissas of the two stress centers:

$$
\frac{s_{1}^{\prime}}{s_{2}^{\prime}}=e^{2 \theta \tan \varphi}
$$

When the inclination of the filling surface behind the wall is $\beta$, the cohesion between soil elements is assumed to be as follows:

$$
c_{m}=c \cdot \frac{\tan \beta}{\tan \varphi} .
$$

Stress circle 1 (Figure 5) after the deflection of the principal stress is caused by the filling with an inclined surface; the following geometric relations can be obtained:

$$
\begin{gathered}
O^{\prime} M=O^{\prime} H_{1}+H_{1} M, \\
O^{\prime} H_{1}=s_{1}^{\prime} \cos \beta, \\
H_{1} M=\sqrt{r_{1}^{2}-H_{1} R_{1}^{2}}=s_{1}^{\prime} \sqrt{\sin ^{2} \varphi-\sin ^{2} \beta} .
\end{gathered}
$$

The principal stress of soil element of the cohesive fill due to inclined surface is as follows:

$$
\begin{gathered}
O M=\gamma z \cos \beta, \\
\sigma_{z z}^{\prime}=\gamma z \cos ^{2} \beta+c \cot \varphi .
\end{gathered}
$$

The following equation can be obtained through geometric analysis

$$
O^{\prime} M=\frac{\sigma_{z z}^{\prime}}{\cos \beta}=s_{1}^{\prime}\left(\cos \beta+\sqrt{\sin ^{2} \varphi-\sin ^{2} \beta}\right) .
$$




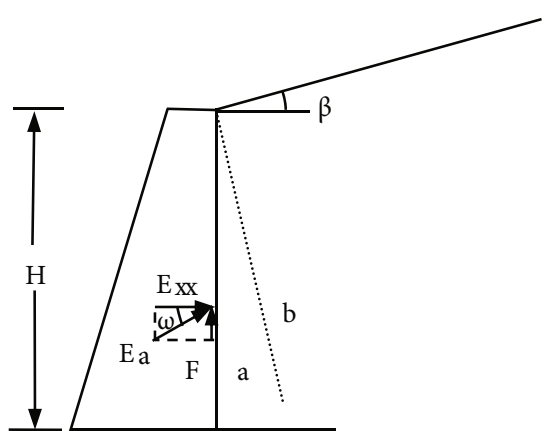

FIgURE 4: Retaining wall under active limit state.

According to stress circle 2 (Figure 5) after deflection of the principal stress direction caused by friction and bonding force between the wall and the fill, the following geometric relations can be obtained:

$$
\begin{gathered}
O^{\prime} H_{2}=s_{2}^{\prime} \cos \delta, \\
H_{2} A=\sqrt{r_{2}^{2}-H_{2} R_{2}^{2}}=s_{2}^{\prime} \sqrt{\sin ^{2} \varphi-\sin ^{2} \delta} \\
O^{\prime} A=O^{\prime} H_{2}-H_{2} A=s_{2}^{\prime}\left(\cos \delta-\sqrt{\sin ^{2} \varphi-\sin ^{2} \delta}\right), \\
\sigma_{x x}^{\prime}=O^{\prime} A \cos \delta .
\end{gathered}
$$

The following equation can be obtained through geometric analysis:

$$
\sigma_{x x}^{\prime}=s_{2}^{\prime} \cos \delta\left(\cos \delta-\sqrt{\sin ^{2} \varphi-\sin ^{2} \delta}\right) .
$$

The formula is further deformed to

$$
\begin{aligned}
\sigma_{x x}^{\prime}= & \frac{s_{2}^{\prime}}{s_{1}^{\prime}} \frac{\cos \delta\left(\cos \delta-\sqrt{\sin ^{2} \varphi-\sin ^{2} \delta}\right)}{\cos \beta+\sqrt{\sin ^{2} \varphi-\sin ^{2} \beta}} \cdot \frac{\left(\gamma z \cos ^{2} \beta+c \cot \varphi\right)}{\cos \beta} \\
= & \frac{\cos \delta\left(\cos \delta-\sqrt{\sin ^{2} \varphi-\sin ^{2} \delta}\right)}{\cos \beta\left(\cos \beta+\sqrt{\sin ^{2} \varphi-\sin ^{2} \beta}\right)} e^{-2 \theta \tan \varphi} \cdot\left(\gamma z \cos ^{2} \beta+c \cot \varphi\right) .
\end{aligned}
$$

The horizontal component of the active earth pressure strength is as follows:

$$
\begin{aligned}
\sigma_{x x}= & \sigma_{x x}^{\prime}-l=\frac{\cos \delta\left(\cos \delta-\sqrt{\sin ^{2} \varphi-\sin ^{2} \delta}\right)}{\cos \beta\left(\cos \beta+\sqrt{\sin ^{2} \varphi-\sin ^{2} \beta}\right)} e^{-2 \theta_{a} \tan \varphi} \\
& \cdot\left(\gamma z \cos ^{2} \beta+c \cot \varphi\right)-c \cot \varphi=K_{a 1 x} \gamma z \\
& +K_{a 2 x} c \cot \varphi-c \cot \varphi,
\end{aligned}
$$

where

$$
\begin{gathered}
K_{a 1 x}=\frac{\cos \delta \cos \beta\left(\cos \delta-\sqrt{\sin ^{2} \varphi-\sin ^{2} \delta}\right)}{\cos \beta+\sqrt{\sin ^{2} \varphi-\sin ^{2} \beta}} e^{-2 \theta_{a} \tan \varphi}, \\
K_{a 1 x}=\frac{\cos \delta\left(\cos \delta-\sqrt{\sin ^{2} \varphi-\sin ^{2} \delta}\right)}{\cos \beta\left(\cos \beta+\sqrt{\sin ^{2} \varphi-\sin ^{2} \beta}\right)} e^{-2 \theta_{a} \tan \varphi} .
\end{gathered}
$$

The vertical component of the active earth pressure strength is as follows:

$$
\begin{aligned}
\tau= & O^{\prime} A \sin \delta=\frac{s_{2}^{\prime}}{s_{1}^{\prime}} \frac{\sin \delta\left(\cos \delta-\sqrt{\sin ^{2} \varphi-\sin ^{2} \delta}\right)}{\cos \beta+\sqrt{\sin ^{2} \varphi-\sin ^{2} \beta}} \\
& \cdot \frac{\left(\gamma z \cos ^{2} \beta+c \cot \varphi\right)}{\cos \beta} \\
= & \frac{\sin \delta\left(\cos \delta-\sqrt{\sin ^{2} \varphi-\sin ^{2} \delta}\right)}{\cos \beta\left(\cos \beta+\sqrt{\sin ^{2} \varphi-\sin ^{2} \beta}\right)} e^{-2 \theta_{a} \tan \varphi} \\
& \cdot\left(\gamma z \cos ^{2} \beta+c \cot \varphi\right) \\
= & K_{a 1 y} \gamma z+K_{a 2 y} c \cot \varphi,
\end{aligned}
$$

where

$$
\begin{gathered}
K_{a 1 y}=\frac{\sin \delta \cos \beta\left(\cos \delta-\sqrt{\sin ^{2} \varphi-\sin ^{2} \delta}\right)}{\cos \beta+\sqrt{\sin ^{2} \varphi-\sin ^{2} \beta}} e^{-2 \theta_{a} \tan \varphi}, \\
K_{a 2 y}=\frac{\sin \delta\left(\cos \delta-\sqrt{\sin ^{2} \varphi-\sin ^{2} \delta}\right)}{\cos \beta\left(\cos \beta+\sqrt{\sin ^{2} \varphi-\sin ^{2} \beta}\right)} e^{-2 \theta_{a} \tan \varphi} .
\end{gathered}
$$

The strength of the active earth pressure is as follows:

$$
\sigma_{a}=\sqrt{\sigma_{x x}^{2}+\tau^{2}}
$$

The depth of the tension crack on the surface of cohesive fill is as follows:

$$
\begin{gathered}
z_{0}=\frac{c \cot \varphi-K_{a 2 x} c \cot \varphi}{K_{a 1 x} \gamma}, \\
h=H-z_{0} .
\end{gathered}
$$

The soil within the depth of the cracked soil layer is equivalent to the uniformly distributed load

$$
q=\gamma z_{0}
$$

The vertical component of the active earth pressure is as follows: 


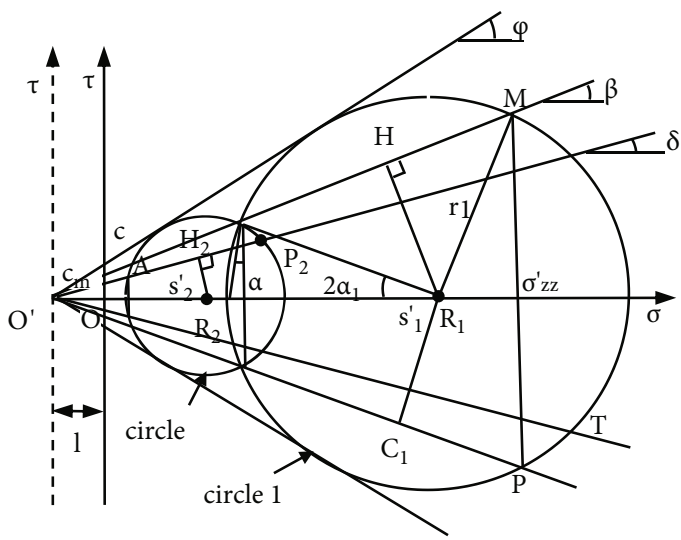

(a)

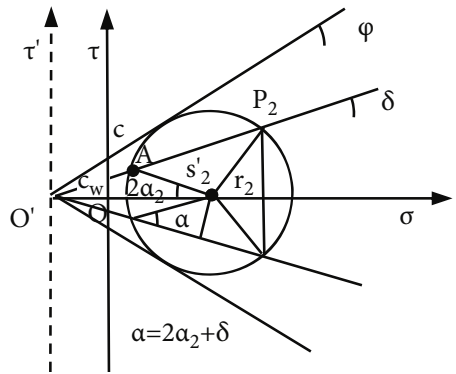

(b)

FIGURE 5: The active earth pressure stress circle.

$$
F=\int_{0}^{h} \tau d z=K_{a 1 y}\left[\frac{1}{2} \gamma h^{2}+q h\right]+K_{a 2 y} \operatorname{ch} \cot \varphi
$$

The horizontal component of the active earth pressure is as follows:

$E_{x x}=\int_{0}^{h} \sigma_{x x} d z=K_{a 1 x}\left[\frac{1}{2} \gamma h^{2}+q h\right]+K_{a 2 x} \operatorname{ch} \cot \varphi-\operatorname{ch} \cot \varphi$

The active earth pressure is as follows:

$$
E_{a}=\sqrt{E_{x x}^{2}+F^{2}}
$$

The included angle between the action direction of passive earth pressure and the normal of the wall back is as follows:

$$
\omega_{a}=\arctan \frac{F}{E_{x x}} .
$$

From circle 1 in Figure 5, the following is obtained:

$$
H_{1} R_{1}=O^{\prime} R_{1} \sin \beta=\frac{r_{1}}{\sin \varphi} \sin \beta
$$

therefore,

$$
\sin \left(2 \alpha_{1}+\beta\right)=\frac{\sin \beta}{\sin \varphi}
$$

From circle 2 in Figure 5, the following is obtained:

$$
\begin{aligned}
H_{2} R_{2}=O^{\prime} R_{2} \sin \delta & =\frac{r_{2}}{\sin \varphi} \sin \delta, \\
\sin \left(2 \alpha_{2}+\delta\right) & =\frac{\sin \delta}{\sin \varphi} .
\end{aligned}
$$

It can be seen from Figure 5 that

$2 \theta_{a}=2\left(\alpha_{2}-\alpha_{1}\right)=\arcsin \left(\frac{\sin \delta}{\sin \varphi}\right)-\arcsin \left(\frac{\sin \beta}{\sin \varphi}\right)-\delta+\beta$,

where $\alpha_{1}$ is the deflection angle of principal stress of the cohesive soil element caused by the inclined surface of the cohesive backfill behind the wall and $\alpha_{2}$ is the deflection angle of the principal stress of the cohesive soil element caused by the friction and bonding force between the retaining wall and the backfill.

According to Figure 5, the bonding force of the wall-soil interface can be expressed as

$$
c_{w}=c \cdot \frac{\tan \delta}{\tan \varphi} .
$$

If the back of the wall is smooth $(\delta=0)$ and the backfill level $(\beta=0)$, then $\theta_{a}=0, c_{w}=0$, and Equation (45) degenerates into the following equation:

$$
E_{a}=\frac{1}{2} \gamma H^{2} K_{a}-2 c H \sqrt{K_{a}}+\frac{2 c^{2}}{\gamma} \text {, }
$$

where

$$
K_{a}=\frac{1-\sin \varphi}{1+\sin \varphi}=\tan ^{2}\left(45^{\circ}-\frac{\varphi}{2}\right) .
$$

This means that for the retaining wall with horizontal backfill, the calculation formula of the active earth pressure in this paper is equal to the formula of Rankine active earth pressure without considering the effect of friction and bonding force of the wall-soil interface.

\section{Comparative Analysis Based on Examples}

Example 1. The height of a retaining wall is $8 \mathrm{~m}$, the back of the wall is vertical, the filling behind the wall is horizontal, 


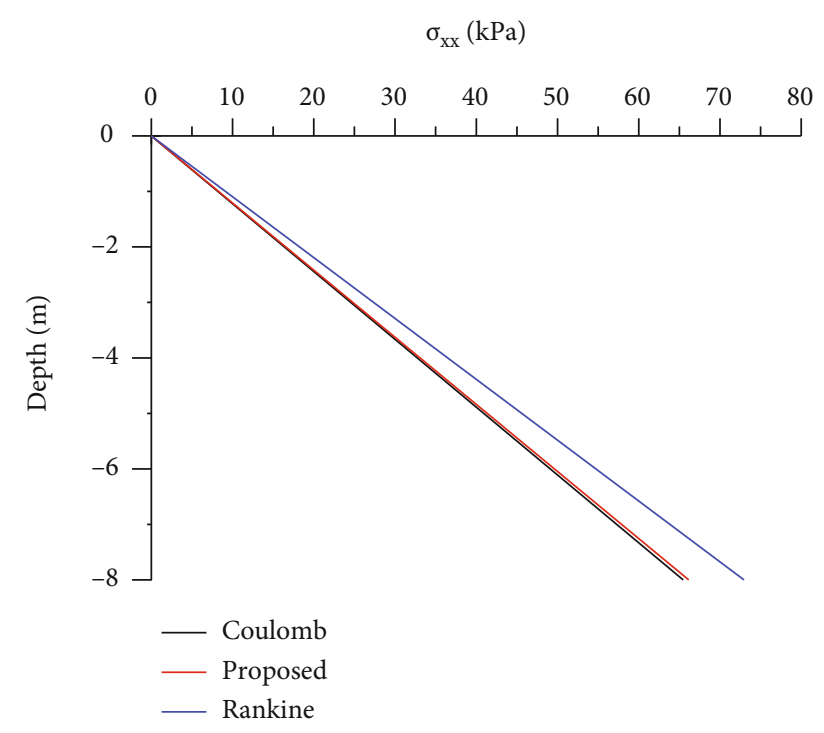

Figure 6: Comparison of horizontal components of the active earth pressure.

and there is no overload on the surface of the filling behind the wall. The parameters of filling material are $\gamma=18.6$ $\mathrm{kN} / \mathrm{m}^{3}, c=0 \mathrm{kPa}, \varphi=20^{\circ}, \delta=10^{\circ}$. The calculation results are shown in Figures 6 and 7.

It can be seen from Figures 6 and 7 that the horizontal components of active and passive earth pressures obtained by the proposed method are between the calculation results of Rankine's theory and Coulomb's theory, which are similar to the calculation results of Coulomb's theory considering wall-soil friction. Both the proposed method in this paper and Coulomb's theory consider the effect of wall-soil friction, but these methods are different; thus, the calculation results are different, but the calculation results are in a reasonable range as a whole.

Example 2. The height of a retaining wall is $10 \mathrm{~m}$, the wall back is vertical, and the gravity of filling is $18.6 \mathrm{kN} / \mathrm{m}^{3}, \varphi$ $=25^{\circ}$, the inclination of the backfill material $\beta=0^{\circ}$, take $c$ $=0,2,5,8,10,15,18,20,25 \mathrm{kPa}$, the angle of wall-soil friction $\delta=0.5 \varphi$.

Tables 1 and 2 show the earth pressure and its horizontal and vertical components obtained by the proposed method and Rankine's theory. The proposed method in this paper considers the friction and bonding force of the wall-soil interface, so there is also a vertical component along the back of the wall besides the horizontal force acting vertically on the back of the wall. The calculation method of Rankine's theory does not fully consider the interaction between the wall and backfill, and the calculated result is only a horizontal force, which is inconsistent with the actual force of the wall.

For the active earth pressure (Table 1), the results obtained by the proposed method are less than that obtained by Rankine's theory, and the results obtained by both methods decrease with the increase of the cohesion of the

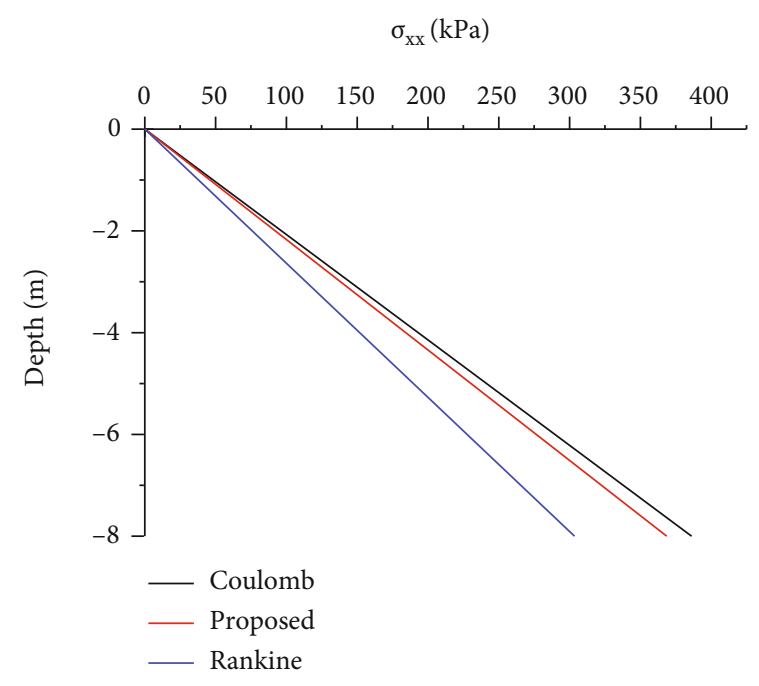

FIgURE 7: Comparison of horizontal components of the passive earth pressure.

fill. When the cohesion of the fill is small, the horizontal component of the active earth pressure decreases with the increase of the cohesion of the fill, but the reduction speed is relatively slow. The value of the vertical component caused by the friction of the wall-soil interface changes little, while the bonding force of the wall-soil interface increases with the increase of the cohesion of the fill. The vertical component caused by the bonding force of the wall-soil interface increases obviously; the vertical component of active earth pressure increases as a whole. When the cohesion of the fill is large, the reduction rate of the horizontal component of the active earth pressure is accelerated, and the reduction of the vertical component caused by the friction of the wall-soil interface is also increased, while the bonding force of the wall-soil interface increases with the increase of the cohesion of the fill. The vertical component caused by the bonding force of the wall-soil interface is increasing, but the reduction of the vertical component caused by the friction of the wall-soil interface is more significant, while the vertical component of the active earth pressure decreases continuously as a whole. The proportion of the vertical component of the active earth pressure increases with the increase of the cohesion of the fill.

For the passive earth pressure (Table 2), the results obtained by the proposed method are greater than that obtained by Rankine's theory, and the results obtained by both methods increase with the increase of the cohesion of the fill. With the increase of cohesion of fill, the horizontal component of passive earth pressure increases, and the vertical component of earth pressure caused by wall soil interface friction also increases. The bonding force of the wallsoil interface increases with the increase of the cohesion of the fill, and the vertical component caused by the bonding force of the wall-soil interface is also increasing. The horizontal and vertical components of the passive earth pressure increase with the increase of the cohesion of the fill.

The earth pressure acting on the back of the wall is no longer horizontal because of the friction and bonding force 
TABLE 1: The horizontal and vertical components of the active earth pressure $(\mathrm{kPa})$.

\begin{tabular}{|c|c|c|c|c|c|c|}
\hline \multirow{2}{*}{$c(\mathrm{kPa})$} & \multicolumn{3}{|c|}{ Proposed method } & \multicolumn{3}{|c|}{ Rankine’s theory } \\
\hline & Horizontal component & Vertical component & Resultant force & Horizontal component & Vertical component & Resultant force \\
\hline 0 & 337.25 & 74.77 & 345.44 & 377.45 & 0 & 377.45 \\
\hline 2 & 310.47 & 77.95 & 320.10 & 352.40 & 0 & 352.40 \\
\hline 5 & 272.37 & 81.75 & 284.37 & 316.43 & 0 & 316.43 \\
\hline 8 & 236.77 & 84.36 & 251.34 & 282.40 & 0 & 282.40 \\
\hline 10 & 214.41 & 85.44 & 230.81 & 260.79 & 0 & 260.79 \\
\hline 15 & 163.38 & 85.86 & 184.57 & 210.52 & 0 & 210.52 \\
\hline 18 & 136.09 & 84.53 & 160.21 & 182.94 & 0 & 182.94 \\
\hline 20 & 119.28 & 82.99 & 145.31 & 165.63 & 0 & 165.63 \\
\hline 25 & 82.10 & 76.84 & 112.45 & 126.12 & 0 & 126.12 \\
\hline
\end{tabular}

TABLE 2: The horizontal and vertical components of the passive earth pressure $(\mathrm{kPa})$.

\begin{tabular}{|c|c|c|c|c|c|c|}
\hline \multirow{2}{*}{$c(\mathrm{kPa})$} & \multicolumn{3}{|c|}{ Proposed method } & \multicolumn{3}{|c|}{ Rankine's theory } \\
\hline & Horizontal component & Vertical component & Resultant force & Horizontal component & Vertical component & Resultant force \\
\hline 0 & 2996.01 & 664.20 & 3068.75 & 2291.44 & 0 & 2291.44 \\
\hline 2 & 3091.29 & 694.83 & 3168.42 & 2354.23 & 0 & 2354.23 \\
\hline 5 & 3234.21 & 740.78 & 3317.96 & 2448.41 & 0 & 2448.41 \\
\hline 8 & 3377.13 & 786.73 & 3467.56 & 2542.59 & 0 & 2542.59 \\
\hline 10 & 3472.41 & 817.36 & 3567.31 & 2605.38 & 0 & 2605.38 \\
\hline 15 & 3710.62 & 893.94 & 3816.78 & 2762.34 & 0 & 2762.34 \\
\hline 18 & 3853.54 & 939.89 & 3966.50 & 2856.53 & 0 & 2856.53 \\
\hline 20 & 3948.82 & 970.52 & 4066.33 & 2919.31 & 0 & 2919.31 \\
\hline 25 & 4187.02 & 1047.10 & 4315.96 & 3076.28 & 0 & 3076.28 \\
\hline
\end{tabular}

of the wall-soil interface, and the direction of the earth pressure is constantly changing under the influence of wall-soil parameters. The proposed method in this paper considers the interaction between the wall and the backfill. The action direction of the earth pressure is given, which is more consistent with the mechanical principle than Rankine's theory.

\section{Influence of Fill Inclination and Cohesion on Earth Pressure}

The height of the retaining wall is $10 \mathrm{~m}$, the back of the wall is vertical, and the filling weight is $\gamma=18.6 \mathrm{kN} / \mathrm{m}^{3}$, while the internal friction angle $\varphi=20^{\circ}, \delta=0.5 \varphi, \beta=0^{\circ}, 5^{\circ}, 10^{\circ}, 15^{\circ}$, and $c=0,5,10,15,20,25,30 \mathrm{kPa}$. These parameters are taken to analyze the influence of $\beta$ and $c$ on earth pressure. The results obtained by the proposed method in this paper are shown in Figures 8 and 9.

Figures 8 and 9, respectively, reflect the change of the active and passive earth pressures with $c$ and $\beta$. It can be seen that the active earth pressure decreases with the increase of $c$, but the decreasing rate is gradually slowing down. In addition, the active earth pressure increases with the increase of $\beta$, and the increasing rate is gradually accelerated with the increase of $\beta$. The passive earth pressure increases with the increase of $c$ and $\beta$.

\section{Conclusions}

Considering the influence of the backfill with inclined surface and the friction and bonding force at the wall-soil interface, the principal stress rotation method is used to deal with the principal stress deflection of the soil element behind the wall, and the calculation formulas of active and passive earth pressure of the retaining wall with cohesive fill are derived. Based on the comparison of the new formula with previous studies and parameter sensitivity analysis, the following conclusions are obtained:

(1) Lancellota's passive earth pressure formula for the retaining wall with inclined cohesionless fill and the formulas of Rankine's active and passive earth pressure are special cases of the proposed method, and the proposed method presented in this paper is more universal

(2) The earth pressure on the back of the wall obtained by the proposed method in this paper includes horizontal and vertical components, while Rankine's theory does not fully consider the interaction between the wall and the backfill, and the result is only the horizontal force. The horizontal components of active and passive earth pressure obtained by the proposed method in this paper are between the calculated results of Rankine's theory and Coulomb's 


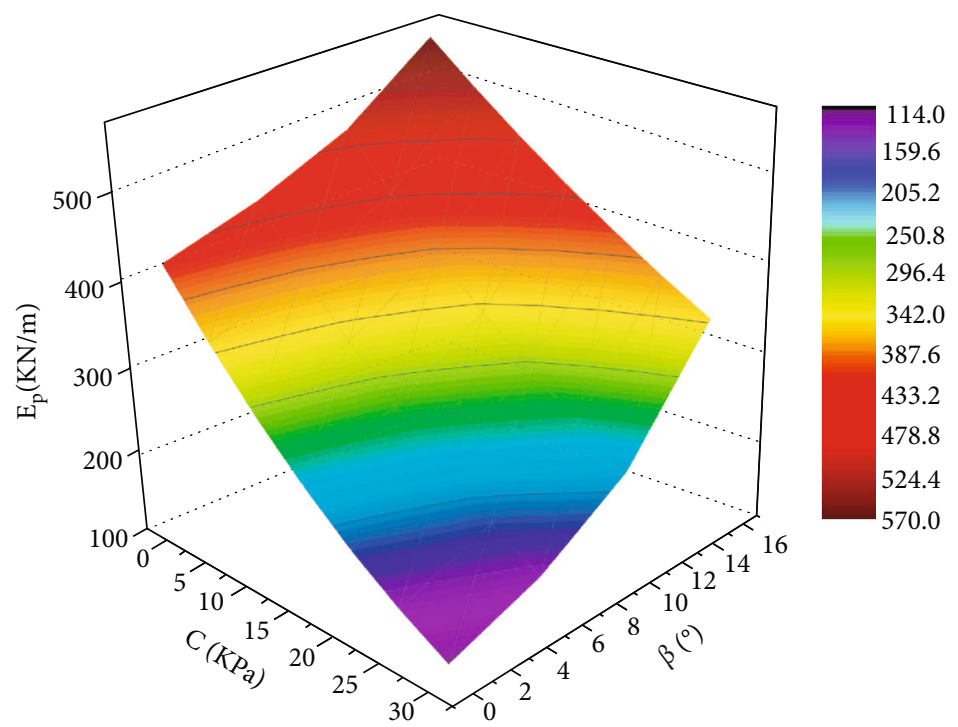

Figure 8: Change of active earth pressure with $c$ and $\beta$.

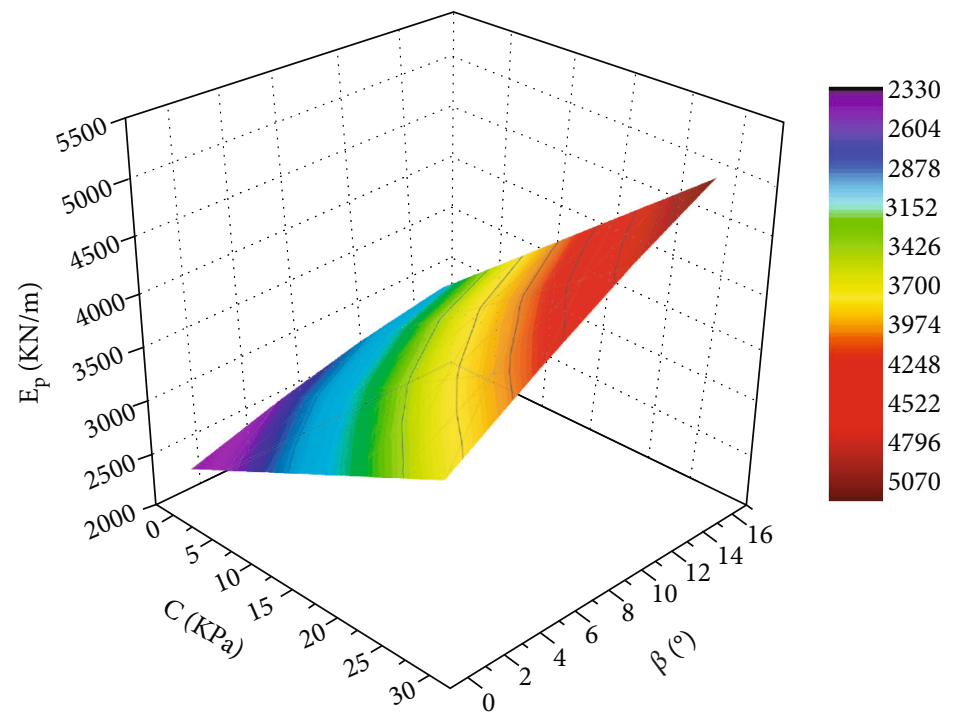

FIGURE 9: Change of passive earth pressure with $c$ and $\beta$.

theory, which are similar to the results of Coulomb's theory considering wall-soil friction

(3) The active earth pressure and its horizontal component decrease with the increase of the cohesion of the fill, while the passive earth pressure and its horizontal component increase with the increase of the cohesion of the fill. Both the active and passive earth pressures increase with the increase of the inclination of the fill, and the increasing speed is gradually accelerated

\section{Appendix}

In order to study the geometric relationship between the stress centers of regions $a$ and $b$, the deviation diagram of stress circle centers is drawn (Figure 10). There is a common point $X$ in the two stress circles, and the direction of $X$ acting on the ele-

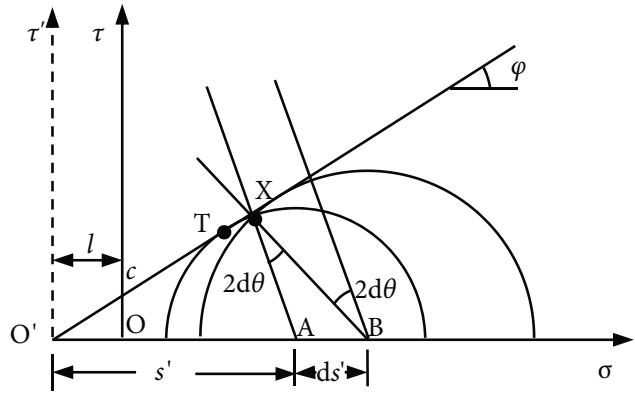

Figure 10: Deviation diagram of stress circle centers.

ments corresponding to the stress circles at center $A$ and center $B$ is inconsistent, and there is a deviation angle $d \theta$. In order to make them consistent, the latter is rotated $d \theta$, and the corresponding rotation angle on the stress circle is $2 d \theta$. 
For the triangle $A B X$, the sine theorem is applied:

$$
\frac{B X}{\cos \varphi}=\frac{d s^{\prime}}{\sin 2 d \theta}
$$

When $d s^{\prime} \longrightarrow 0$, the two circles tend to coincide, the common point $X \longrightarrow T$, and there is $\sin \theta \cong \theta, B X \cong A X$. The above formula becomes

$$
\frac{s^{\prime} \sin \varphi}{\cos \varphi}=\frac{d s^{\prime}}{2 d \theta} .
$$

The formula is further deformed to

$$
\frac{d s^{\prime}}{s^{\prime}}=2 d \theta \tan \varphi
$$

Integrating Equation (A.3) according to Figure 3, the following can be obtained:

$$
\frac{s_{1}^{\prime}}{s_{2}^{\prime}}=e^{2 \theta \tan \varphi} .
$$

Equation (4) is proved.

\section{Notations}

$c_{w}$ : Bonding force of wall-soil interface $(\mathrm{kPa})$

$c$ : Cohesion of the fill $(\mathrm{kPa})$

$\varphi: \quad$ Internal friction angle of the fill $\left(^{\circ}\right)$

$\delta$ : $\quad$ Angle of wall-soil friction $\left({ }^{\circ}\right)$

$\beta$ : Inclination of the fill $\left(^{\circ}\right)$

$\sigma: \quad$ Earth pressure strength $(\mathrm{kPa})$

$\sigma_{x x}$ : Normal component of earth pressure strength $(\mathrm{kPa})$

$c_{m}$ : Cohesion between soil elements of inclined fill $(\mathrm{kPa})$

$\sigma_{z z}$ : Normal stress of inclined fill element $(\mathrm{kPa})$

$\tau_{z z}$ : Shear stress of inclined fill element $(\mathrm{kPa})$

$E_{\mathrm{a}}$ : Active earth pressure $(\mathrm{kN} / \mathrm{m})$

$E_{\mathrm{p}}$ : Passive earth pressure $(\mathrm{kN} / \mathrm{m})$

$\tau$ : Vertical component of passive earth pressure strength (kPa)

$\gamma$ : Unit weight of the backfill material $\left(\mathrm{kN} / \mathrm{m}^{3}\right)$

$H$ : Depth of the backfill (m)

$z$ : $\quad$ Depth of calculation $(\mathrm{m})$

$z_{0}$ : Thickness of upper zone $(\mathrm{m})$

$\theta: \quad$ Rotation angle of principal stress direction $\left({ }^{\circ}\right)$

$\theta_{\mathrm{a}}$ : Rotation angle of principal stress under active state $\left(^{\circ}\right)$

$\theta_{\mathrm{p}}$ : Rotation angle of principal stress under passive state $\left(^{\circ}\right)$

$\omega_{\mathrm{a}}$ : Angle between the action direction of active earth pressure and the normal of wall back $\left(^{\circ}\right)$

$\omega_{\mathrm{p}}$ : Angle between the action direction of passive earth pressure and the normal of wall back $\left({ }^{\circ}\right)$.

\section{Data Availability}

The data used to support the findings of this study are available from the corresponding author upon request.

\section{Conflicts of Interest}

No potential conflict of interest was reported by the authors.

\section{Acknowledgments}

This work was supported by the National Natural Science Foundation of China (U1810203) and the Doctoral Fund Project of Henan Polytechnic University (648198).

\section{References}

[1] Y. Z. Wang, "Distribution of earth pressure on a retaining wall," Géotechnique, vol. 50, no. 1, pp. 83-88, 2000.

[2] K. H. Paik and R. Salgado, "Estimation of active earth pressure against rigid retaining walls considering arching effects," Géotechnique, vol. 53, no. 7, pp. 643-653, 2003.

[3] M. H. Khosravi, T. Pipatpongsa, and J. Takemura, “Theoretical analysis of earth pressure against rigid retaining walls under translation mode," Soils and Foundations, vol. 56, no. 4, pp. 664-675, 2016.

[4] M. H. Khosravi, A. R. Kargar, and M. Amini, "Active earth pressures for non-planar to planar slip surfaces considering soil arching," International Journal of Geotechnical Engineering, vol. 14, no. 7, pp. 730-739, 2020.

[5] D. Choudhury and S. Nimbalkar, "Seismic passive resistance by pseudo-dynamic method," Géotechnique, vol. 55, no. 9, pp. 699-702, 2005.

[6] S. Ghosh and R. Prasad Sharma, "Seismic active earth pressure on the back of battered retaining wall supporting inclined backfill," International Journal of Geomechanics, vol. 12, no. 1, pp. 54-63, 2012.

[7] A. Pain, Q. S. Chen, S. Nimbalkar, and Y. T. Zhou, "Evaluation of seismic passive earth pressure of inclined rigid retaining wall considering soil arching effect," Soil Dynamics and Earthquake Engineering, vol. 100, pp. 286-295, 2017.

[8] A. Pain, D. Choudhury, and S. K. Bhattacharyya, "Seismic stability of retaining wall-soil sliding interaction using modified pseudo-dynamic method," Géotechnique Letters, vol. 5, no. 1, pp. 56-61, 2015.

[9] V. N. Khatri, "Determination of passive earth pressure with lower bound finite elements limit analysis and modified pseudo-dynamic method," Geomechanics and Geoengineering, vol. 14, no. 3, pp. 218-229, 2019.

[10] A. Gupta and V. A. Sawant, "Effect of soil amplification on seismic earth pressure using pseudo-dynamic approach," International Journal of Geotechnical Engineering, vol. 15, no. 1, pp. 40-51, 2021.

[11] A. Maskar and S. Madhekar, "Seismic earth pressure computation using modified Dubrova's model," Journal of GeoEngineering, vol. 14, no. 2, pp. 53-64, 2019.

[12] Z. H. Mazindrani and M. H. Ganjali, "Lateral earth pressure problem of cohesive backfill with inclined surface," Journal of Geotechnical and Geoenvironmental Engineering, vol. 123, no. 2, pp. 110-112, 1997.

[13] N. Gnanapragasam, "Active earth pressure in cohesive soils with an inclined ground surface," Canadian Geotechnical Journal, vol. 37, no. 1, pp. 171-177, 2000.

[14] S. K. Shukla, S. K. Gupta, and N. Sivakugan, “Active earth pressure on retaining wall for $\mathrm{c}-\phi$ soil backfill under seismic 
loading condition," Journal of Geotechnical and Geoenvironmental Engineering, vol. 135, no. 5, pp. 690-696, 2009.

[15] S. K. Shukla, "Dynamic active thrust from_c - $\phi_{-}$soil backfills," Soil Dynamics and Earthquake Engineering, vol. 31, no. 3, pp. 526-529, 2011.

[16] J. G. Peng and Y. P. Zhu, "Simplified method for calculating active earth pressure against rigid retaining walls for cohesive backfill," Soil Mechanics and Foundation Engineering, vol. 55, no. 6, pp. 374-379, 2019.

[17] K. Ghaffari Irdmoosa and H. Shahir, "Analytical solution for active earth pressure of $\mathrm{c}-\varphi$ soil considering arching effect," Geomechanics and Geoengineering, vol. 14, no. 2, pp. 71-84, 2019.

[18] K. G. Irdmoosa and H. Shahir, "Analytical solution for passive earth pressure of $c-\varphi$ soil using principal stress rotation assumption," Journal of GeoEngineering, vol. 14, no. 1, pp. 31-39, 2019.

[19] T. H. Lu, "A formula of active earth pressure including cohesion and adhesion," Rock and Soil Mechanics, vol. 23, no. 4, pp. 470-473, 2002.

[20] X. J. Hu, "Improvement on Coulumb accurate solution of active earth pressure to cohesive soil," Chinese Journal of Geotechnical Engineering, vol. 28, no. 8, pp. 1049-1052, 2006.

[21] M. X. Peng, "Coulumb's unified solution of active earth pressure on retaining wall," Rock and Soil Mechanics, vol. 30, no. 2, pp. 379-386, 2009.

[22] F. Vahedifard, B. A. Leshchinsky, K. Mortezaei, and N. Lu, "Active earth pressures for unsaturated retaining structures," Journal of Geotechnical and Geoenvironmental Engineering, vol. 141, article 04015048 , no. 11, 2015.

[23] H. L. Wang, Research on Calculation Method of Earth Pressure of Deep and Large Foundation Pit in Soft Ground, Henan Polytechnic University, Henan, China, 2021.

[24] R. Lancellotta, "Analytical solution of passive earth pressure," Géotechnique, vol. 52, no. 8, pp. 617-619, 2002.

[25] R. Lancellotta, "Lower-bound approach for seismic passive earth resistance," Géotechnique, vol. 57, no. 3, pp. 319-321, 2007.

[26] G. Mylonakis, P. Kloukinas, and C. Papantonopoulos, "An alternative to the Mononobe-Okabe equations for seismic earth pressures," Soil Dynamics and Earthquake Engineering, vol. 27, no. 10, pp. 957-969, 2007.

[27] H. L. Wang, Z. S. Zou, J. M. Liu, and X. Y. Wang, "The earth pressure of retaining wall with cohesive fill based on principal stress rotation," Hydrogeology \& Engineering Geology, vol. 48, no. 4, pp. 64-71, 2021.

[28] K. Terzaghi, Theoretical Soil Mechanics, John Wiley and Sons, New York, USA, 1943.

[29] R. Lancellotta, Geotechnical Engineering, Taylor and Francis, New York, USA, 2009. 